\title{
A Historical and Qualitative Analysis of Different Medical Imaging Techniques
}

\author{
Leena Jain, $\mathrm{PhD}$ \\ Associate Professor \& Head (MCA), \\ GIMET, Amritsar-143001, India
}

\begin{abstract}
:
The growth of medical science realized the need of a device which can be use to view human body from inside and which can also act as an intermediate between doctor and patient. The medical imaging system is used to take internal image of human body and various other body organs and can also perform analysis of those images. In this paper various medical imaging techniques like X-Rays, Ultrasound and Magnetic resonance Imaging (MRI) will be discussed on the basis of various parameters like their history, usage, type of radiation and their physical and mental side effects.
\end{abstract}

\section{Keywords:}

Medical imaging, X-Rays, MRI, Ultrasound, Nuclear Imaging, Noise

\section{INTRODUCTION}

In last few decades, the rapid progress in Medical imaging techniques has completely revolutionized medical diagnostic system. The modern imaging system is not only limited to image production, but also focused on image processing, image transmission, image recording and automated diagnosis [1]. In order to give best treatment doctor needs to examine patient's body from inside. Medical imaging system reveals internal organs hidden by skin and creates visual representation of internal body for diagnosis purpose. Earlier the interpretation of medical images was done by physicians manually i.e. doctor had only 5 senses to examine problem but in these days computer aided diagnosis system acts as an intermediate between doctor and patient, the machine examine patients body and doctor examines the report generated by machine which gives fast, accurate, reliable and consistent results. The study of medical imaging system is interrelated to biological imaging whereas study of sub area of medical science such as neurology, cardiology, orthopedics and areas like radiology, thermograph are prerequisite for study of medical imaging [2]. The X-rays, Magnetic resonance, molecular imaging, optical imaging Ultrasound and radioactivity are some of well known, rapidly growing and frequently used medical diagnostic tools. Now question arises when to use these medical diagnostic tools and how to select best diagnostic tool for a particular problem.

\subsection{TYPES OF RADIATION USED}

The medical imaging techniques use some kind of radiations in order to diagnose internal body organs. The intensity of these radiations depends upon part of body is being examined. These radiations are of different energy level, different frequency and may belong to different level of

\author{
Palwinder Singh \\ Research Scholar, \\ Punjab Technical University Jalandhar, India
}

electromagnetic spectrum. The electromagnetic spectrum has 2 major divisions which are given in figure 1.

a. Ionizing radiations

b. Non-Ionizing radiations

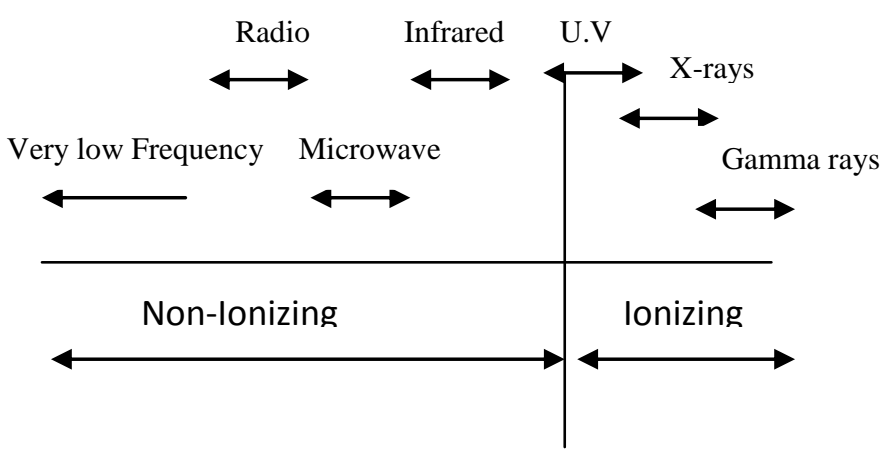

Figure 1 Ionizing and Non Ionizing radiations

Ionizing radiations have sufficient energy to break some chemical bond and remove tightly bound atom from an electron and creates an ions whereas Non-Ionizing radiation can only move atom in a molecule and make them to vibrate. The alpha, beta, gamma rays and radiations produce during Radioactive decay are Ionizing radiations. On the other hand Microwave, Infrared and Ultrasound rays are Non-Ionizing radiations. Non-Ionizing radiations of low intensity can only heat up tissues and its long term effects are not known whereas Ionizing radiations have many severe stochastic and Non-stochastic health effects. Cancer is the primary health effect that can be caused due to Ionizing radiations exposure. These radiations can permanently damage our cells. It can also cause change in our DNA. As all medical imaging techniques uses some kind of radiations. So in this paper health effects of various medical imaging techniques will also be compared [3]

\subsection{WHEN TO USE}

Earlier medical imaging was used for diagnostic purpose but now a days it is being used in preventive and curative medicine. Though medical imaging is sufficient in curing some diseases, but the actual use of medical imaging is in finding disease or cause of disease and evaluating response of treatment [4]. The medical diagnostic technique are used for creating an image of some body parts like bones, stomach , intestines, liver, joints and blood vessels etc. It is used to check baby in the womb. 


\subsection{Evolution of Medical Imaging Techniques:}

Year

1977

1972

1956

Figure 2 Evaluation of Medical Imaging Techniques $[5,6,7,8]$

\section{MEDICAL IMAGING TECHNIQUES:}

\subsection{Rays}

History of medical imaging system began in nineteenth century with the X-Rays, discovered by German physicist Wilhelm roentgen. X-ray imaging takes advantage of high frequency characteristics of electromagnetic rays which when passes through human body, absorbed in different amount depending upon density of tissue. [9]. For medical imaging, $\mathrm{X}$-Rays are produced in vacuum tubes by attacking a metal with very high speed electrons which then passes through human body and produce an image on photographic plate. The $\mathrm{X}$-ray image of roentgen's wife hand is given in figure 3 . Computerized Tomography (CT-Scan) is also an X-ray based technique developed by godfrey Hounsfield [10]. Computerized Tomography uses pile of $\mathrm{x}$-ray images from different angles to produce virtual three dimensional image of inside body. The procedure begins with single slice of body which then repeated along different slices, to produce a dimensional image of a part of the body. Though X-rays is quick and non-invasive technique but as an ionizing radiation it has several side effects. The High dose of X-Rays can damage DNA in cells. The exposure to X-Rays can also increase the risk of cancer around .08\% [11].

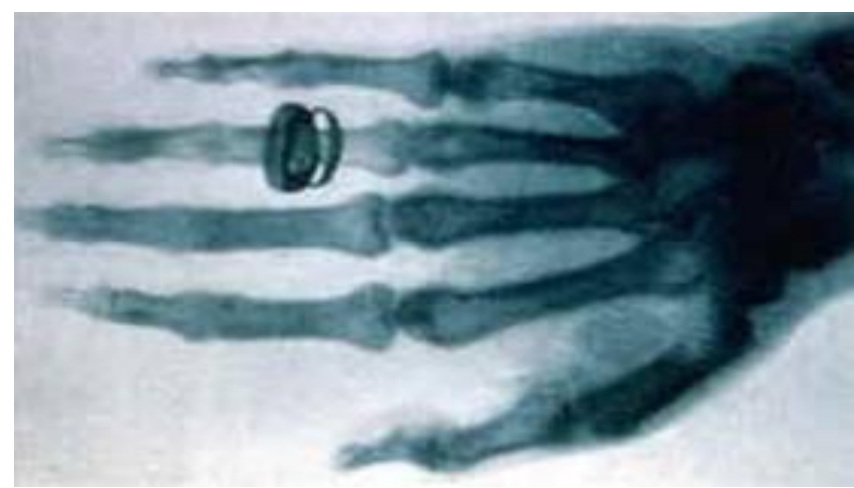

Figure 3 X-Ray Image of Roentgen's wife Hand

\section{Ultrasound Imaging:}

Ultrasound or acoustical imaging is a medical imaging technique that uses high frequency sound waves and their echoes. In addition, ultrasound images have the advantage of being portable, versatile, and not requiring ionizing Radiations[12]. Moreover the diagnosis procedure in ultrasound is of low cost and in order to diagnose an illness, person need not to go through dangerous invasive procedures. The Study related to ultrasound was started in 1794 by lazaro spallanzani but In 1942 Karl Dussik introduced ultrasound in the field of diagnostic. Ultrasound waves travels freely through fluid and soft tissues however it reflected back when it collides with some solid surface. These reflected sound waves are displayed as an image on moniter. It is a part of routine check up in case of pregnancy, where it is used to check fetus in womb. The Ultrasound image of fetus is given in figure 4. The advancement of ultrasound imaging is Doppler ultrasonography. Doppler ultrasound records sound waves reflected from moving objects. If body or organ is moving then echo comes back at different frequency which is Doppler effect. Ultrasound imaging is used to check position of fetus in womb whereas Doppler Ultrasound can also check heartbeat of fetus. When long term side effects of X-Rays were not known , it was common practice to use X-Rays for diagnosis in pregnancy but later study on 700,000 children born between 1947 and 1964 in 37 major hospitals revealed that cancer mortality of children whose mother received XRays during pregnancy is $40 \%$ higher than the children whose mother had not gone for the X-Rays diagnosis[13]. Unlike XRays ultrasound are non-ionizing radiation so it doesnot have same risks as that of X-Rays. Sometime when ultrasound enters in body that can heats the tissues slightly. But even then major risks and long term effects are not known . when we compare Ultrasound imaging with other diagnostic techniques like X-Rays, MRI, Nuclear Imaging it turns out to be most cost effective than other techniques[14]

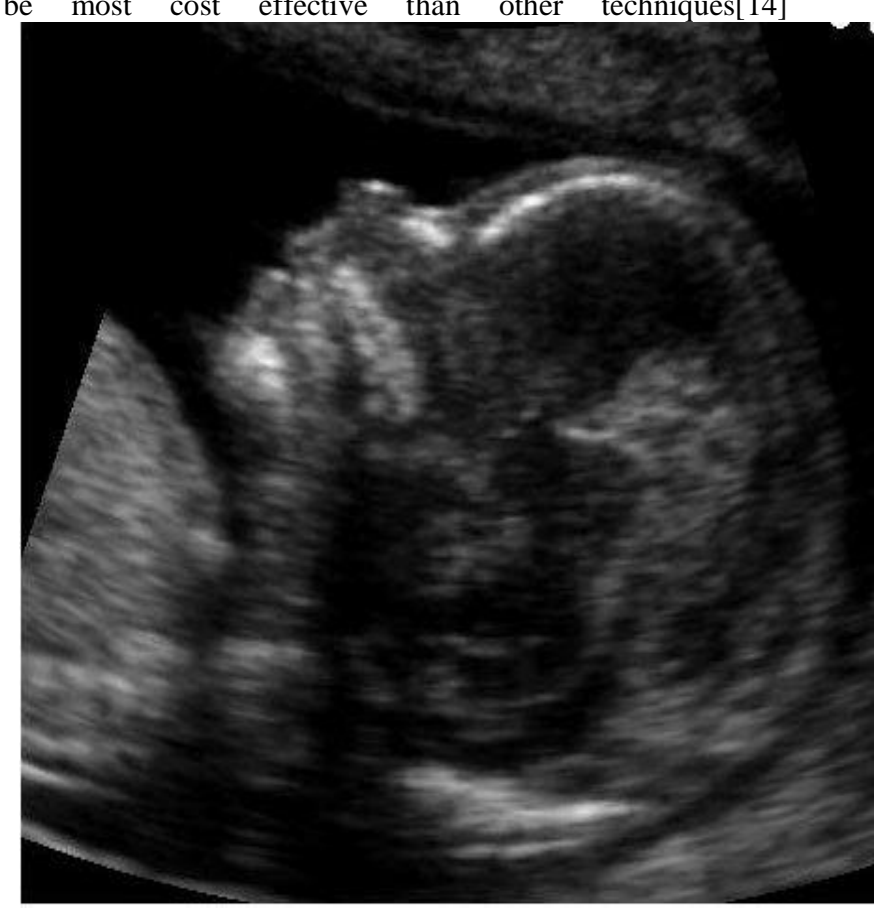

Figure 4 Ultrasound Image of Unborn baby 


\subsection{Magnetic Resonance Imaging:}

MRI is non invasive medical diagnostic technique that uses magnetic fields and radio waves to show body organs, tissues etc. It was developed by Raymond damadian. But discovery was not accidental actually it was gradual enhancement of some inventions, which was started by joseph fourier, his mathematical model was first used for magnetic resonance signal analysis by Richard Ernst, then Raymond damadian in 1974 published a technique ' field focusing NMR' (nuclear magnetic resonance) which contained an image of scanned volume element through a mouse[15,16,17].

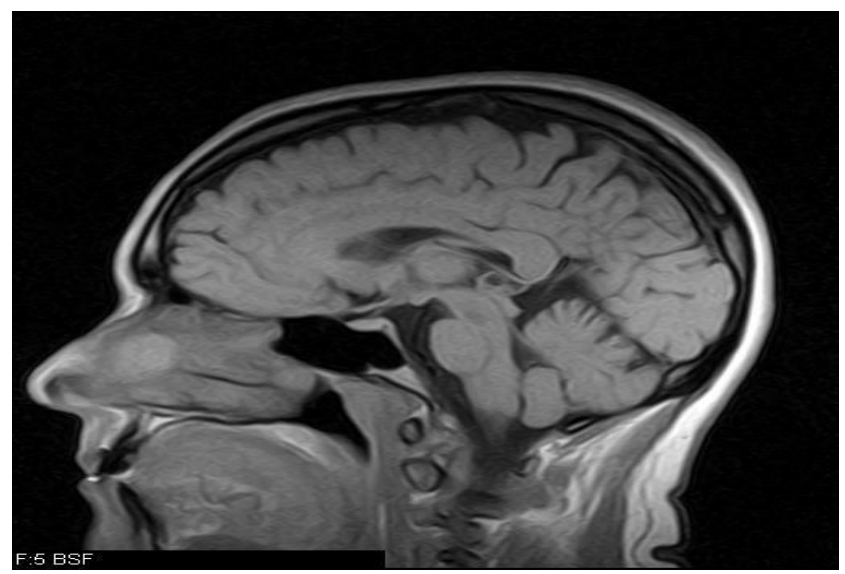

Figure 5 MRI Scan of Human brain

In MRI very strong radio waves which are 20000 times stronger than earth's magnetic field are sent through the human body. These radio waves compel hydrogen atom in the body to vibrate, and radiation which these hydrogen atoms emit are detected outside the body and forms an image with the help of computer. The MRI of human brain is given in figure 5. It ignores bones as they contains very small water content it mainly focuses on soft tissues. It does not uses Ionizing radiations so this technique is relatively safer than other techniques which uses Ionizing radiations like X-Rays. But in this case slight movement can ruin the image even breathing can caus artifacts or image distortions. Contrast medium is required in this case which can have many adverse effects. The Contrast medium is generally injected into a vein of a hand or arm that contrast medium may cause allergic reactions. MRI can be used to evaluate heart, liver, blood vessels, kidney, bladder etc $[18,19]$. The visualization of abnormal tissues is better in case of MRI.

\subsection{Nuclear Imaging:}

It involves injecting or inhaling some radioactive material which emits gamma rays and those emitted gamma rays are used by scanner to produce an image. This radioactive substance may be injected, swallowed or inhaled. The amount of radioactive substance used should be properly selected to provide least exposure to patient but which also ensure a correct test[20]. The best use of nuclear imaging is in detecting cancer as it has ability to detect how far cancer has been grown. Otherwise it can also be used to detect various infections, injuries and recurrent diseases. The rays emitted by radioactive material are ionizing radiations that may cause injection site reaction otherwise it is painless and non-invasive technique. Nuclear imaging is the combined study of chemistry, physics, medicine, mathematics and computer science. The positron emission tomography (PET) and single photon emission computed tomography (SPECT) are types of nuclear imaging. In PET scan the chemical changes that take place in a tissue are recorded as an image. PET also uses images produced by photos but PET provides more detailed image. The PET scan of human brain is given in figure 6. In SPECT scan small amount of controlled radioactive drug is injected into patient's body and radiations emitted by that radioactive substance are recorded as a image.

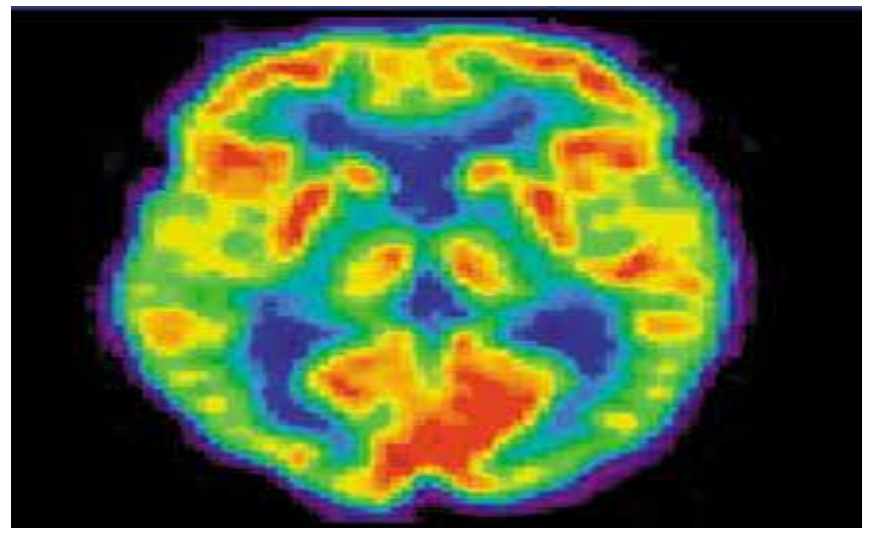

Figure 6 PET Scan of Human brain

\section{COMPARISON OF DIFFERENT MEDICAL IMAGING TECHNIQUES:}

The Comparison of various medical imaging techniques on the basis of different parameters like radiation type, cost, health effects, technical problems is given below in Table 1 .

Table 1 Comparison of different medical imaging techniques

\begin{tabular}{|c|c|c|c|c|c|}
\hline & X-ray & CT Scan & MRI & $\begin{array}{l}\text { Ultra } \\
\text { Sound }\end{array}$ & $\begin{array}{l}\text { Nuclear } \\
\text { Imaging }\end{array}$ \\
\hline $\begin{array}{l}\text { Types of } \\
\text { Radiation }\end{array}$ & Ionizing & Ionizing & $\begin{array}{l}\text { Non } \\
\text { Ionizing }\end{array}$ & Non ionizing & Ionizing \\
\hline Radiation used & $\mathrm{X}$-rays & $\mathrm{X}$-rays & $\begin{array}{l}\text { Electromagnetic } \\
\text { Radio waves }\end{array}$ & $\begin{array}{l}\text { High frequency } \\
\text { Sound waves }\end{array}$ & Radioactive isotopes \\
\hline
\end{tabular}




\begin{tabular}{|c|c|c|c|c|c|}
\hline Image type & Transmissive & Transmissive & Emissive & Reflective & Emissive \\
\hline Unit to measure & $\begin{array}{l}\text { Msv } \\
\text { Millisievert }\end{array}$ & $\begin{array}{l}\text { MSv } \\
\text { Millisievert }\end{array}$ & $\begin{array}{l}\text { Tesla (for } \\
\text { magnetic field) }\end{array}$ & Hertz & $\begin{array}{l}\text { Becquerel (unit of } \\
\text { radioactivity) }\end{array}$ \\
\hline $\begin{array}{l}\text { Typically Used to } \\
\text { check }\end{array}$ & $\begin{array}{l}\text { Bone Injuries } \\
\text { Infections } \\
\text { Arthiritis }\end{array}$ & $\begin{array}{l}\text { Bones injuries } \\
\text { Cancer detection } \\
\text { Lungs exam }\end{array}$ & $\begin{array}{l}\text { Tumor of chest } \\
\text { Angiography } \\
\text { Uterine } \\
\text { abnormalities }\end{array}$ & $\begin{array}{l}\text { Health of Fetus } \\
\text { Breast cancer } \\
\text { Swelling }\end{array}$ & $\begin{array}{l}\text { Coronary artery disease } \\
\text { Infection } \\
\text { Cancer }\end{array}$ \\
\hline $\begin{array}{l}\text { Technical } \\
\text { problems }\end{array}$ & $\begin{array}{l}\text { Quantum Noise or } \\
\text { Random noise }\end{array}$ & $\begin{array}{l}\text { Quantum Noise or } \\
\text { Random noise }\end{array}$ & Rician Noise & Speckle Noise & Random Noise \\
\hline Side effect & $\begin{array}{l}\text { Increases a risk of } \\
\text { cancer by } 0.08 \%\end{array}$ & $\begin{array}{l}\text { Increases a risk of } \\
\text { cancer }\end{array}$ & $\begin{array}{l}\text { Contrast medium } \\
\text { may cause kidney } \\
\text { problem . }\end{array}$ & $\begin{array}{l}\text { Excessive dose may } \\
\text { burn tissues, but } \\
\text { relatively less side } \\
\text { effects }\end{array}$ & $\begin{array}{l}\text { Injection site reaction in } \\
\text { some peoples. }\end{array}$ \\
\hline Cost & Very low & High & Very high & Low & Very high \\
\hline Contrast agent & No & No & Yes & No & Yes \\
\hline
\end{tabular}

\section{SELECTION OF IMAGING TECHNIQUE:}

The process of finding appropriate medical imaging technique is a matter of decision making. The first step of decision making is identifying the problem. In this case medical problem of a patient is considered and for that particular problem which organs are needs to identify internally. In next step different alternatives are generated and for evaluating them different aspects of medical imaging techniques must be known. The following aspects are evaluated before making any decision.

4.1 Cost : The cost of medical imaging technique is the first aspect to be studied. It needs to be verified that for this given problem how much money should be spend.

4.2 Availability: The availability of tool must ensure and also ensure that is there any social restriction on this tool.

4.3 Suitability: The main aspects which we should check that which imaging technique will give best result for a problem which we want to diagnose.

4.4 Physical effects: The negative effects of different alternatives must be considered while making final selection

4.5 Mental effects: The negative effects of different medical imaging techniques on mental health must be known while making final selection.
While evaluating different alternatives information about strong and weak points of each technique is arranged in structured way. There will be a weight for a each criteria and imaging technique with maximum weight will be selected. The benefit of given decision making procedure is that you can defend your choice of appropriate imaging technique and will also get good results.

\section{RECENT ADVANCEMENTS IMAGING TECHNOLOGIES:}

The PET CT Scan and PET MR scan are two recent advancements in diagnostic technologies. In PET the radioactive isotopes are used to trace physiological functions and Computerized tomography to outline anatomic structure whereas in PET MRI scan radioactive isotopes are used to trace physiological functions and Magnetic Resonance Imaging is used to outline anatomic structure. Both PET CT Scan and PET MRI scan are very lengthy procedures which may takes 2-3 hours to diagnose properly. The frequent use of such advancements is found in detecting blood flow, metastatic disease, brain activities and cancer.

\section{CONCLUSION AND FUTURE WORK:}

In this paper, various medical imaging techniques like X-ray, Ultrasound, MRI, Nuclear Imaging have been discussed. The analysis is on the basis of various parameters like Radiation type, Cost, Contrast agent, Noise model, Technical Problems, and various physical and mental health effects. The above 
table shows comparative analysis of different imaging techniques. The techniques like X-Rays, CT Scan and Nuclear imaging are Ionizing radiations which are harmful whereas Ultrasound and MRI uses Non Ionizing radiations which are less harmful. In Future the various noise models of different medical imaging techniques will be discussed because denoising is the most important preprocessing step before proceeding with image processing so various restoration techniques which are used reduce noise will be applied. Based on the factors like cost, uses, technical problems and side effects it is concluded that the Ultrasound is the most cost effective and safe medical imaging technique.

\section{REFRENCES:}

[1] Kunio dio , "diagnostic imaging over last 50 years: research and development in medical imaging science \&technology”, phys.med.biol.51(2006) R5-R27

[2] D. Ganguly, S. chakraborty and Tai hoon kim "A cognitive study on medical imaging", international journal of bioscience and biotechnology, Vol. 2, no 3, september 2010

[3] www.epa.gov/radiation/understand/ ionize_nonionize. html visited on 12/5/2014

[4] The WHO manual of diagnostic ultrasound . vol 1- $2^{\text {nd }}$ ed

[5] Tal Geva, " Magnetic Resonance Imaging: Historical Perspective", Journal of cardio vascular magnetic resonance 2006, 573-580

[6] http://www.infinityugent.be/research-development/ahistory-of-medical-imaging visited on 11/04/2014

[7] EC Beckmann ,'CT scan early days", International journal of radiology, radiation oncology and all related sciences march 05, 2014

[8] R.C. Gonzalez and R.E. Woods, Digital Image Processing, 2nd ed. Englewood Cliffs, NJ: Prentice-Hall; 2002.

[9] L.muhammad and Z. Muhd Zain, I.E, Mumtaz Begum, "enhancement of bone fracture image using filtering techniques", the international journal of video and image processing and network security. Vol. 9 (10)
[10] http://www.imaginis.com/faq/history-of-medicaldiagnosis-and-diagnostic-imaging\#digital-imagingtechniques visited on 06/06/2014

[11] Brenner, D and C.Ellison (2004, july)" estimated radiation risk with full body CT screening.radiology",232, 735-738. Retrieved 28, nov 2004

[12] http://www.infinityugent.be/research-development/ahistory-of-medical-imaging visited on 14/08/2014

[13] SN weingart , LI lezzoni , "looking for medical injuries where light is bright", JAMA 2003 oct 2008; 290(14):1917-9

[14] S. michelle bierig, A jones, "Accuracy and Cost Comparison of Ultrasound Versus Alternative Imaging Modalities, Including CT, MR, PET, and Angiography", journal of diagnostic medical sonography, , 01/2009

[15] Grattan guiness I, Fourier JBJ,Joseph Fourier, 17681830 , "a survey of his life and work , based on critical edition of his monograph of the propagation of heat", presented to the institute de france in 1870 . Cambridge : MIT Press , 1972

[16] damadian $\mathrm{R}$, minkoff $\mathrm{L}$, goldsmith $\mathrm{M}$ koutcher $\mathrm{J}$, "Tumour imaging in a live animal by focusing NMR" ,Physiol chem. Phys1976;8:61-5

[17] damadian R , minkoff L, goldsmith Mkoutcher J, "field focusing nuclear magnetic resonance: visualization of a tumour in live animal science" 1976;8:61-5

[18] Tsai-goodman B, geva T, odegard KC, sena LM, powell AJ, "clinical role, accuracy and technical aspects of cardiovascular magnetic resonance imaging in infants", AM J Cardiol 2004;94:69-74

[19] Geva T, Sahn, DJ, Powell AJ, "Magnetic resonance imaging of congenital heart disease in adults". Progress in pediatric cardiology 2003;17:21-39

[20] L.koller,"The evolution of medical imaging technologies:electric meat and physician's shifting gaze", vol. 2, no. 3. ISSN 1852-4680, march -2011 